\title{
BMJ Open Electronic, mobile and telehealth tools for vulnerable patients with chronic disease: a systematic review and realist synthesis
}

\author{
Sharon Parker, ${ }^{1}$ Amy Prince, ${ }^{2}$ Louise Thomas, ${ }^{1}$ Hyun Song, ${ }^{1}$ Diana Milosevic, ${ }^{3}$ \\ Mark Fort Harris, ${ }^{1}$ On behalf of the IMPACT Study Group
}

To cite: Parker S, Prince A, Thomas L, et al. Electronic, mobile and telehealth tools for vulnerable patients with chronic disease: a systematic review and realist synthesis. BMJ Open 2018;8:e019192. doi:10.1136/ bmjopen-2017-019192

Received 23 August 2017 Revised 6 March 2018 Accepted 13 March 2018
Check for updates

${ }^{1}$ Centre for Primary Health Care and Equity, University of New South Wales, Sydney, New South Wales, Australia

${ }^{2}$ South Western Sydney Primary Health Network, Campbelltown, New South Wales, Australia ${ }^{3}$ Planning Unit, South Western Sydney Local Health District, Sydney, New South Wales, Australia

Correspondence to

Ms Sharon Parker;

sharon.parker@unsw.edu.au

\section{ABSTRACT}

Objectives The objective of this review was to assess the benefit of using electronic, mobile and telehealth tools for vulnerable patients with chronic disease and explore the mechanisms by which these impact patient self-efficacy and self-management.

Design We searched MEDLINE, all evidence-based medicine, CINAHL, Embase and PsychINFO covering the period 2009 to 2018 for electronic, mobile or telehealth interventions. Quality was assessed according to rigour and relevance. Those studies providing a richer description ('thick') were synthesised using a realist matrix.

Setting and participants Studies of any design conducted in community-based primary care involving adults with one or more diagnosed chronic health condition and vulnerability due to demographic, geographic, economic and/or cultural characteristics. Results Eighteen trials were identified targeting a range of chronic conditions and vulnerabilities. The data provided limited insight into the mechanisms underpinning these interventions, most of which sought to persuade vulnerable patients into believing they could self-manage their conditions through improved symptom monitoring, education and support and goal setting. Patients were relatively passive in the interaction, and the level of patient response attributed to their intrinsic level of motivation. Health literacy, which may be confounded with motivation, was only measured in one study, and eHealth literacy was not assessed.

Conclusions Research incorporating these tools with vulnerable groups is not comprehensive. Apart from intrinsic motivation, health literacy may also influence the reaction of vulnerable groups to technology. Social persuasion was the main way interventions sought to achieve better self-management. Efforts to engage patients by healthcare providers were lower than expected. Use of social networks or other eHealth mechanisms to link patients and provide opportunities for vicarious experience could be further explored in relation to vulnerable groups. Future research could also assess health and eHealth literacy and differentiate the specific needs for vulnerable groups when implementing health technologies.

\section{Strengths and limitations of this study}

- The use of a comprehensive search and systematic process to identify both quantitative and qualitative data.

- The use of Rameses and Preferred Reporting Items for Systematic Reviews and Meta-Analyses reporting standards.

- Incorporation of theory and mapping against a theoretical framework and realist matrix.

- Limited data identified due to a lack of detailed context provided in the published studies.

\section{BACKGROUND}

Chronic conditions result in significant personal and social burden. ${ }^{1}$ Electronic and telehealth tools are increasingly commonplace, can be provided at relatively low $\operatorname{cost}^{2}$ and incorporate personally relevant health information. ${ }^{3}$ For those vulnerable and underserved community members with chronic or long-term conditions, electronic applications may enhance the reach of health services and the provision of tailored needbased services. ${ }^{45}$ The growing impetus to use these technologies is largely underpinned by their potential to intervene in the course of healthcare and influence the way people deal with their health issues. ${ }^{6}$ There is also an expectation that health technologies will engage consumers in appropriate self-care and self-management, ${ }^{7}$ which within the health delivery sphere, shifts the responsibility solely from the clinician to one that is jointly shared by the health provider and patient.

Electronic health (eHealth) tools incorporate many opportunities for patients to increase their engagement through focused disease-specific learning, options to receive regular feedback and frequent reinforcement (eg, peripheral monitoring devices). ${ }^{8}$ 
Additional inbuilt support functions that assess progress, provide goal setting and problem solving, aim to increase the patient's skill and confidence in managing their health problems. ${ }^{9}$ Supplementary motivational interviewing and cognitive behavioural components can also be provided via the internet, mobile device or telephone. ${ }^{10}$

The claims made by health-related apps, websites and other electronic tools remain largely unverified, and more specifically, little is known about their value for vulnerable and marginalised groups. Within the Innovative Models Promoting Access-to-Care Transformation (IMPACT) programme, we aimed to assess, via a systematic review and realist synthesis, the perceived benefit of using electronic tools to enhance the engagement of vulnerable patients with chronic disease. We used realist methodology as a way of unpacking the complexity surrounding eHealth interventions. ${ }^{11}$ This methodology explains the interplay between context, mechanisms and outcomes ${ }^{12}$ where mechanisms are not activities within the intervention, but the responses by people that are triggered by changes in context. ${ }^{13}$ In this review, we specifically sought to explore mechanisms related to patient self-efficacy and self-management. The impact of these tools on access to healthcare more broadly is the topic of a future manuscript.

\section{Research question}

The objective of this review was to assess the benefit of using electronic, mobile and telehealth tools for vulnerable patients with chronic disease and to explore the mechanisms by which these tools impact patient self-efficacy and self-management.

Our population of interest included adults with one or more diagnosed chronic health conditions. We used the definition of chronic disease provided by the National Public Health Partnership ${ }^{14}$ framework, a seminal Australian resource setting out a strategic framework for the prevention and control of chronic non-communicable diseases in Australia. This framework identified 12 chronic conditions.

The definition of vulnerability was based on the IMPACT study definition: Indigenous/first nation people, culturally and linguistically diverse groups including recently arrived refugee groups, those experiencing socioeconomic hardship and disadvantage (unemployed, low income, those in public housing and homeless) and geographic disadvantage (living in a rural and remote area). For these population groups, these demographic, geographic, economic and/or cultural characteristics impede or compromise access to community-based primary healthcare.

There are many and varied definitions of eHealth, mHealth and telehealth used across the health sector. ${ }^{1}$ For the purpose of this review, we defined these in the following ways:

- eHealth, is the general transfer of health resources and healthcare by electronic means through the internet and telecommunications. ${ }^{15}$
- Mobile health (mHealth) is the delivery of healthcare services via mobile/wireless communication devices such as smartphones and tablets.

- Telehealth describes the use of telecommunication techniques (voice, data and images) for providing telemedicine (remote clinical service delivery), medical education and health education over a distance. ${ }^{16}$ Telehealth encompasses long-distance clinical healthcare, patient and professional health-related education, public health and health administration.

\section{METHODS}

Our processes were based on standard systematic review methodology. ${ }^{17}$ Realist synthesis similarly follows the stages of a traditional systematic review except the appraisal of evidence is theoretically driven and intent on explaining why the intervention works or does not work. ${ }^{18}$ Reporting was guided by the Rameses publication standards for reporting realist synthesis ${ }^{19}$ and the Preferred Reporting Items for Systematic Reviews and Meta-Analyses statement. ${ }^{20}$

We searched MEDLINE, all evidence-based medicine, CINAHL, Embase and PsychINFO covering the period 1 January 2009-12 February 2018. Our basic search strategy (box 1) was modified for use in each database.

The criteria for study selection are described in detail in table 1 . We did not exclude studies based on design as we wanted to collect a richer understanding of the interventions.

Included studies required a description of the $\mathrm{e} / \mathrm{m} /$ telehealth intervention and/or its components. Interventions that did not offer broader patient involvement through coaching/skill improvement components and ongoing skill development were excluded, including those programmes used solely for simple self-monitoring of symptoms. Inpatient hospital-based services were excluded, as were those not presenting evaluative data and those involving primarily children or adolescent populations.

We also selected only studies originating in Organisation for Economic Cooperation and Development (OECD) countries.

\section{Study selection process}

Title and abstract screen were undertaken by at least two authors (SP, AP and LT). For citations requiring full-text review, SP, AP and LT reviewed a subset of papers, with final inclusion determined through joint discussion and review.

\section{Data extraction and study variables}

Data were collected using a five-page data collection form within an Access database incorporating the Reach, Efficacy, Adoption, Implementation, Maintenance (REAIM) framework, ${ }^{21}$ the Template for Intervention Description and Replication (TIDieR) framework, ${ }^{22}$ the Place, Race, Occupation, Gender, Religion, Education, Socioeconomic status, social capital 
Box 1 Search strategy conducted 12 February 2018 and modified for each database

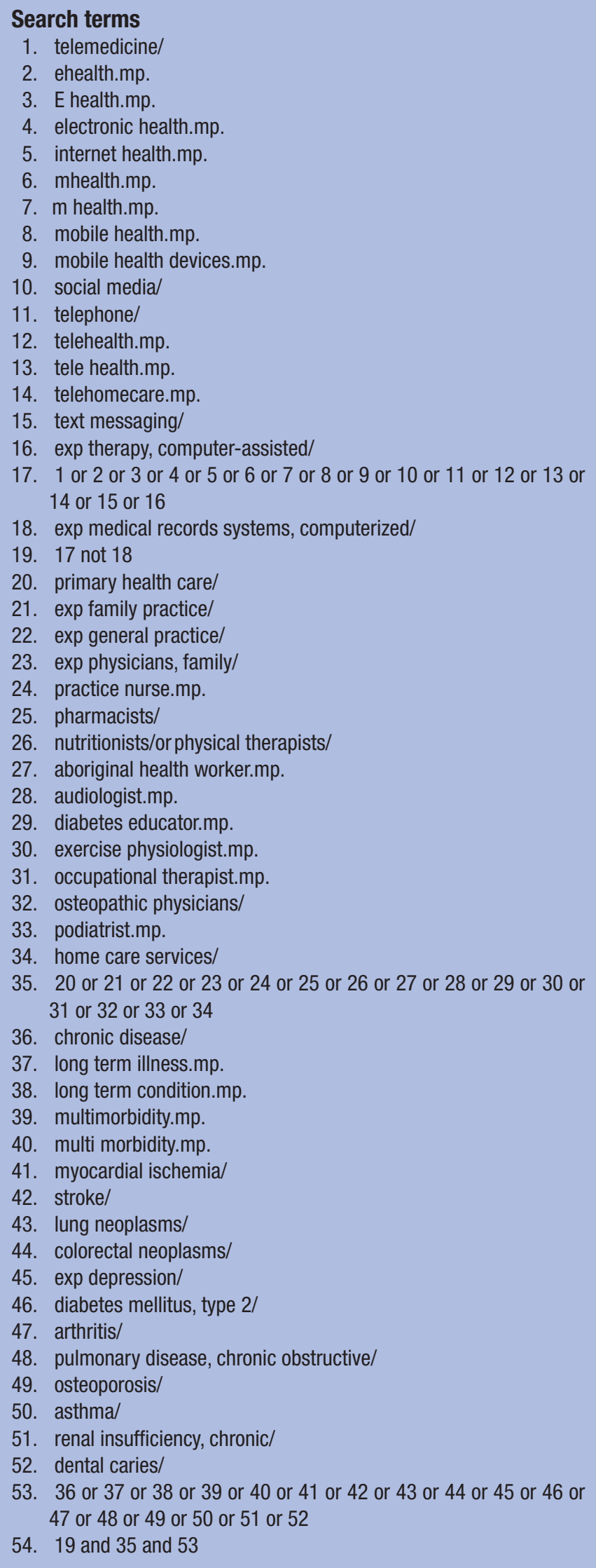

Continued

\section{Box 1 Continued}

55. exp child/or adolescent/

56. 54 not 55

57. editorial.pt.

58. case reports.pt.

59. letter.pt.

60. 57 or 58 or 59

61. 56 not 60

62. limit 61 to (English language and $\mathrm{yr}=$ '2009 -Current')

(PROGRESS) framework ${ }^{23}$ and several predefined variables including study type, country of origin, the procedures, activities and/or processes used in the interventions, supportive activities, recipients and the personnel involved in delivery of the intervention and reported study outcomes. All data extraction was conducted by two authors.

\section{Quality appraisal}

Within realist synthesis, there is no accepted process for assessing quality. Pawson $e t \mathrm{al}^{12}$ argues that quality should not determine inclusion, but a realist synthesis should provide a 'quality filter', ${ }^{24}$ which assesses the contribution of data to rigour (whether the method used to generate the data is credible and trustworthy) and relevance (whether it contributes to theory building and/or testing). ${ }^{19}$

We used a method described by O'Campo et $a t^{25}$ due to recognition that the most useful study information may not be within the reports of studies with the highest quality. Studies were classified against the criteria (table 2) by one author (SP) and confirmed by a second author (AP). Rigour was assessed as 'high', 'moderate' or 'weak' and plotted on a continuum from 0 to 7 . One point was allocated for each positive response and studies graded as high ( 7 points), moderate (4-6 points) and low (0-3 points). Relevance was assessed based on 'thick' or 'thin' descriptions of the intervention components and their mechanisms. One point was allocated for each 'yes' answer and studies considered thick (3-4 points) or thin (0-2 points).

\section{Realist synthesis}

At the core of realist synthesis is to make explicit the underlying assumptions as to how an intervention is supposed to work and to then map the evidence in a systematic way to test and refine this theory. ${ }^{26}$ We developed a linear logic model to explain the engagement of primary care providers and patients in the use of mobile, telehealth and eHealth tools (figure 1). We explored known theories associated with patient self-efficacy and self-management and extracted data against a realist matrix using those included studies that had been assessed as providing a 'thick' description of the intervention. The matrix comprised documented results from each study plus relevant author discussion that attempted to place their results into context. Realist matrices are a complementary approach to 


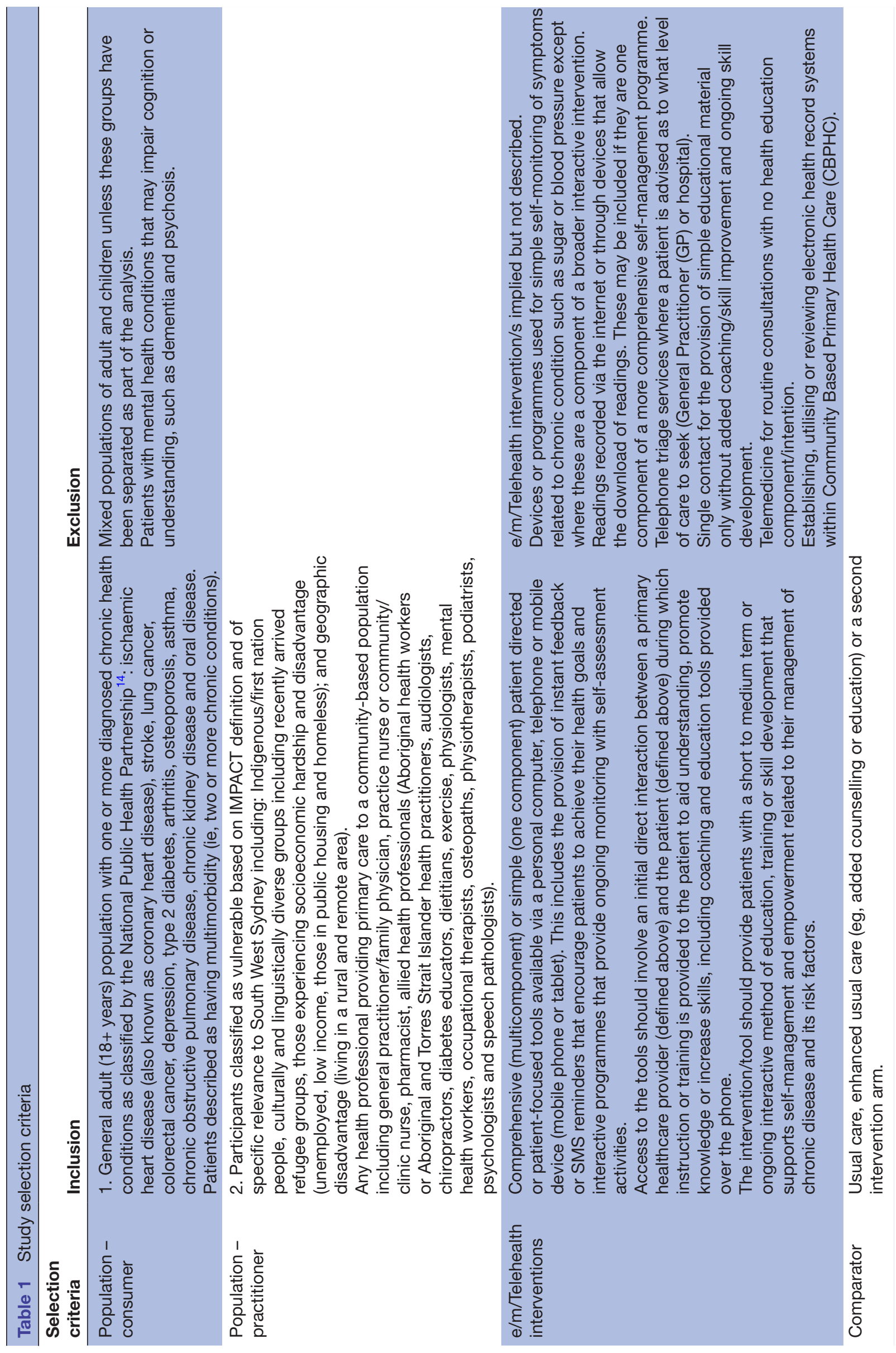

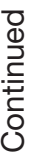




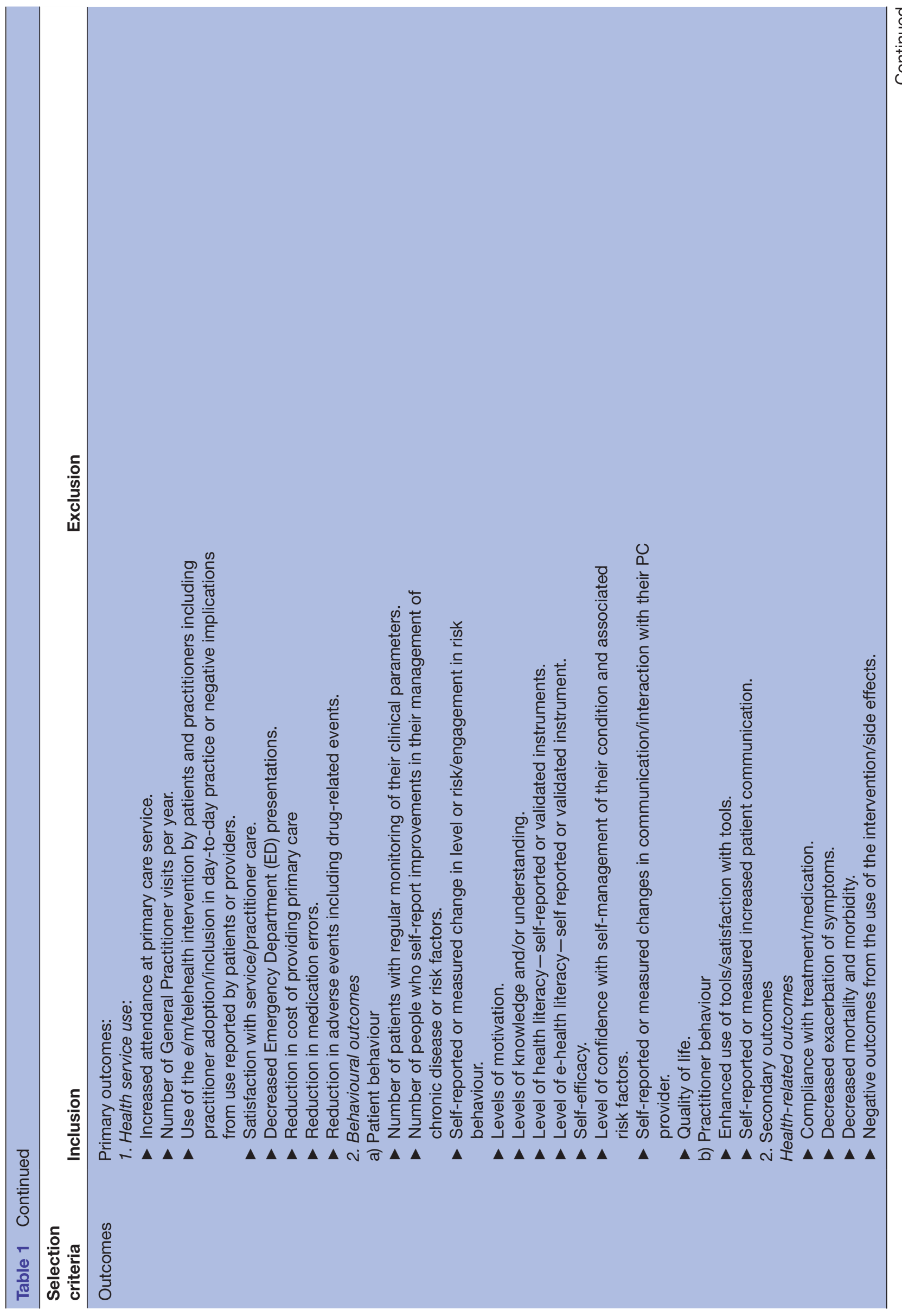


Table 2 Quality appraisal

Assessment of 1 . Is there a clear statement of the aims of rigour the research?

2. Did the study include an appropriate comparison group?

3. Did the study use appropriate eligibility criteria to obtain its target group?

4. Did the study use standardised methods for selecting/putting people into the study and state how they did this?

5. Did the study provide details about sample size?

6. Did the study have a comparatively long study period ( $\geq 6$ months)?

7. Is the methodology appropriate for what they were trying to achieve?

$\begin{aligned} & \text { Assessment of } \\ & \text { relevance }\end{aligned}$
$\begin{aligned} & \text { 2. Is the intervention programme } \\ & \text { description detailed? } \\ & \text { affected programme implementation? }\end{aligned}$
3. Did the study consider reasons for the
results that they achieved?
4. Did the study discuss reasons for
programme success or failure?

Based on: O'Campo et al. ${ }^{25}$

outcome chains and other programme logic models. A realist matrix focuses on the causal mechanisms at work in a programme or project, ${ }^{27}$ and it helps to map the factors from a programme that may be contributing to outcomes by reflecting on:

- Agency: whose actions exactly are causing the change to occur?

- Context: what are the external variables or 'moderators' that affect outcomes? Including the impact of the social and political situation, broad social or geographic features and different population profiles.

- Resources: what resources have been provided or are available?

- Mechanism: how are the resources and the thing/ person being changed interact?

- Outcome: what is the anticipated change relating to self-efficacy and self-management under the specified conditions?

\section{Patient and public involvement}

Our research question was formulated through a collaborative process with the South-Western Sydney Local Innovative Partnership comprising policy makers, healthcare providers and field experts involved in service provision to key vulnerable communities. We did not involve patients directly in this process.

\section{RESULTS}

From 1540 records initially identified, 1111 duplicates were removed, and a further 869 were excluded after title and 


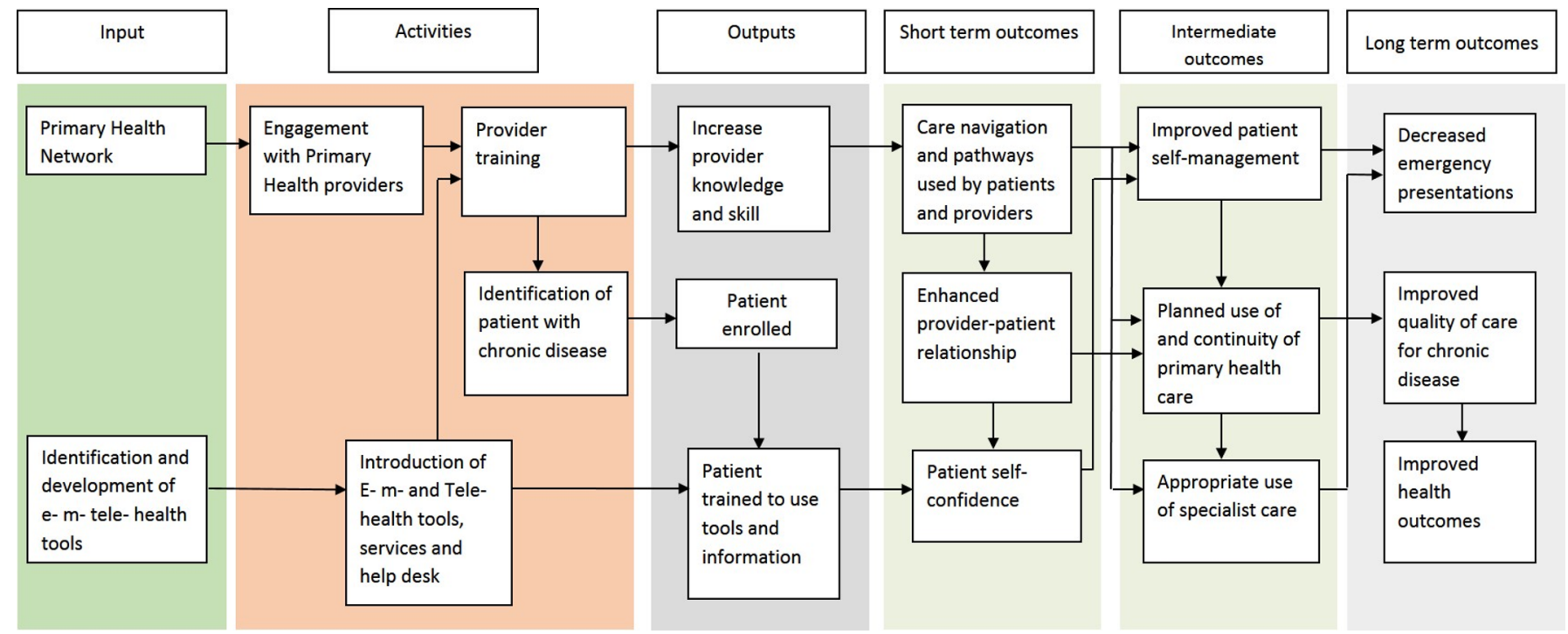

Figure 1 Logic model.

abstract screening. Eligibility was frequently difficult to assess from the title and abstract, so 243 citations underwent a brief full-text review, resulting in 192 exclusions. We identified nine additional related publications that were also eligible. Fifty-nine citations underwent data extraction. Thirty were excluded on the basis that they described simple telemonitoring only, did not provide data related to the intervention, were of an incorrect publication type or contained a population not meeting our definition of vulnerable. Twenty-nine citations relating to 18 separate studies were ultimately included (figure 2). ${ }^{20}$

Randomised controlled trials (RCTs) and cluster RCTs were the predominant study types. Two studies compared alternative interventions. $^{2829}$

\section{Appraisal of studies for rigour and relevance}

Generally, studies were of moderate to high rigour (15/18 studies), and 12/18 studies provided additional valuable contextual information (tables 3-6).

\section{Assessment of self-efficacy and self-management from study reported outcomes}

Studies predominantly assessed a range of clinical and functional outcomes. Several proxy outcomes (that might reasonably be used to make assumptions about the effect on self-efficacy and self-management) were included such as feasibility, satisfaction and acceptability (tables 3-6). Several studies reported positive changes in health behaviour (improved lifestyle indicators), increased compliance and adherence to lifestyle goals and satisfaction with services.

From our logic model, we anticipated that access to reliable electronic tools, supported through a healthcare environment, would enhance patients' ability to obtain, process and understand relevant health information (health literacy), thereby improving efficacy and their capacity to self-manage their chronic condition. The information provided by the studies was inconclusive as to whether this was achieved. Only one study ${ }^{29}$ actively assessed health literacy and tailored their intervention accordingly. No studies assessed e-health literacy.

Overall satisfaction with the use of eHealth and telehealth tools by patients was generally positive. Satisfaction was directly related to the participant's perceived relevance of the tools and the level of positivity in the relationship with the intervention provider. In two studies, ${ }^{30}$ patients expressed high levels of satisfaction from their interaction with nurses, which promoted better understanding of their condition. Others showed high levels of willingness among patients to use telemonitoring equipment $(95 \%)$ and recommend it to others $(90 \%)$ or pay for telehealth services $^{32}$ and a sense that equipment helped them to monitor and improve their health. ${ }^{33}$

\section{Theoretical basis for the interventions}

For most studies, the choice of intervention had no documented theoretical basis. Interventions developed from either a supporting rationale or belief in the benefit of the intervention. These broad principles or frameworks surrounded equitable access, evidence-based medicine, quality improvement, cost effectiveness, better disease management (chronic care and transitional models) and the improvement of health literacy. Only two associated studies specifically commented on the theoretical basis underpinning their intervention. ${ }^{34}$ This incorporated motivational interviewing 'grounded in social cognitive theory constructs of self-efficacy, social support and outcome expectancies, which emphasized the building of participant skills in behaviour change strategies'.

\section{Theory mapping}

We used theory to explore how electronic, mobile and telehealth interventions might influence an individual's response (through learning and behaviour change) towards self-efficacy and self-management. Self-efficacy and self-management are interwoven concepts. Self-efficacy is the sense of patient confidence in their ability to exert 

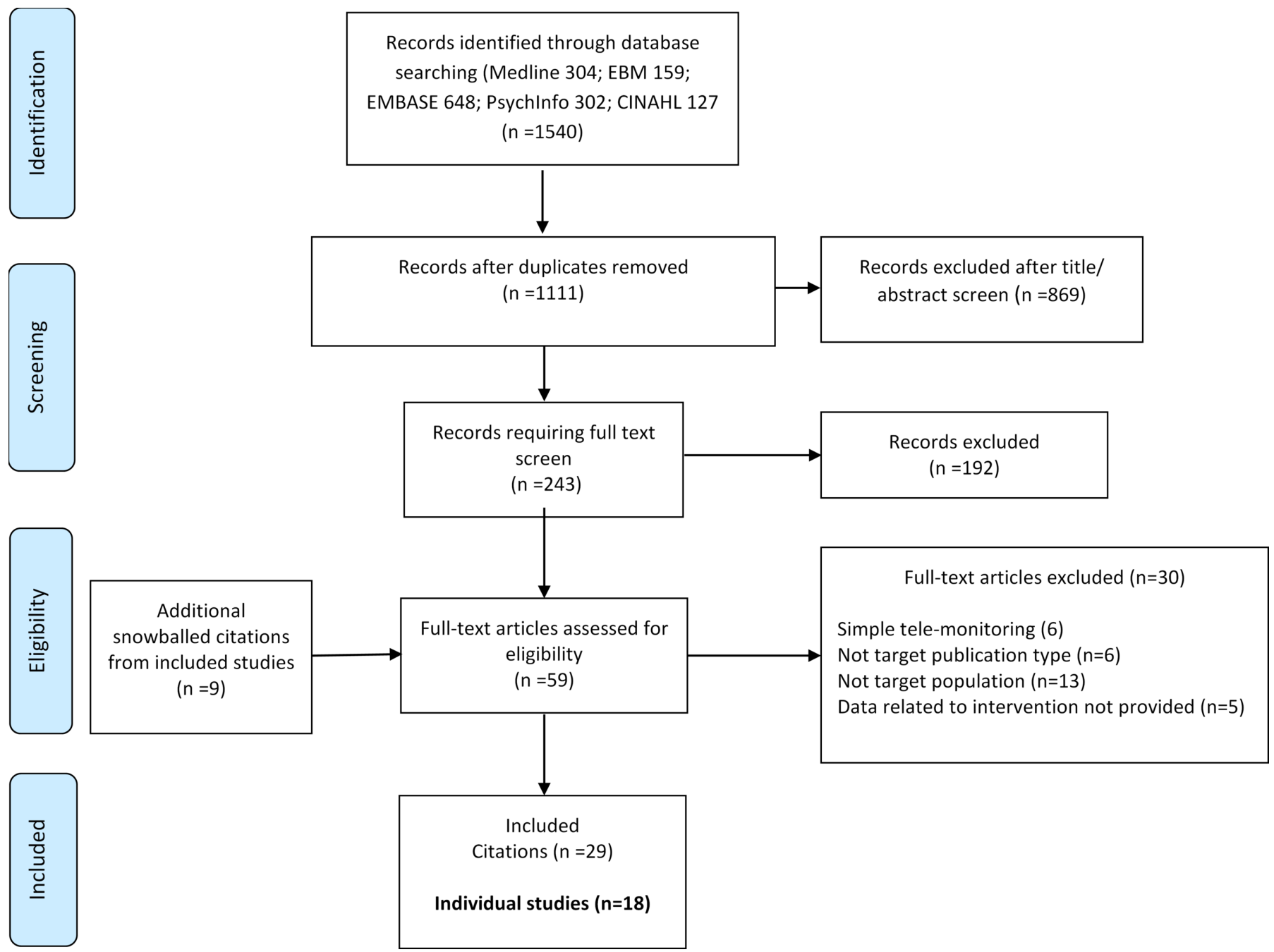

Figure 2 PRISMA flow chart. PRISMA, Preferred Reporting Items for Systematic Reviews and Meta-Analyses.

control over their own motivation, behaviour and social environment, and self-management is active participation by the patient in their own healthcare.

The theory of self-efficacy stems from social cognitive theory and describes the interaction between behavioural, personal and environmental factors in relation to health and chronic disease ${ }^{36}$ Confidence in the ability to perform specific health behaviours will subsequently influence which behaviours patients will engage in ${ }^{36-38}$ and is an important driver of sustained behaviour change. ${ }^{8}$

The components of self-efficacy theory that influences actions are performance accomplishments, vicarious experience, social persuasion and physiological and emotional states. ${ }^{39}$ From our matrix (table 7), the study interventions used a range of resources designed to increase patient skill mastery such as assessment and feedback, ${ }^{34}$ goal setting, ${ }^{28} 2934354041$ workbooks, ${ }^{29} 3435$ websites and training to use tools. ${ }^{33} 4142$ Additional resource materials that encouraged participation or guided participants through the intervention process were frequently provided and translated. ${ }^{32} 43$

Mastery with the 'technology divide' was inbuilt in some interventions but not all. Self-efficacy can be enhanced by observing and interacting with those who have had similar experiences (ie, via vicarious experience). When we observe others succeed through sustained effort (eg, lose weight), this raises our beliefs that we too possess the capabilities to master the activities needed for success in that area.

Within the included studies vicarious experience was not overtly targeted with the exception of the study by Cherrington $e t a l,{ }^{40}$ which used peer community health workers (with diabetes or caring for someone with diabetes) to link patients with diabetes to primary care via a web application and telephone coaching.

The largest concentration of effort within the interventions related to social persuasion or those activities where people are led, through suggestion, into believing that they can achieve a task. This was provided through motivational interviewing to manage expectations, ${ }^{35} 40$ behavioural activation approaches ${ }^{2833404144}$ and counselling. ${ }^{29} 44$ Activities were purposefully designed to provide encouragement (eg, goal setting), were easily attainable and focused on achievements and rewards. ${ }^{35}$ Physical and/or psychological morbidities were common among the populations, and due to the negative judgements and emotional reactions that go hand in hand with these conditions, significant effort 


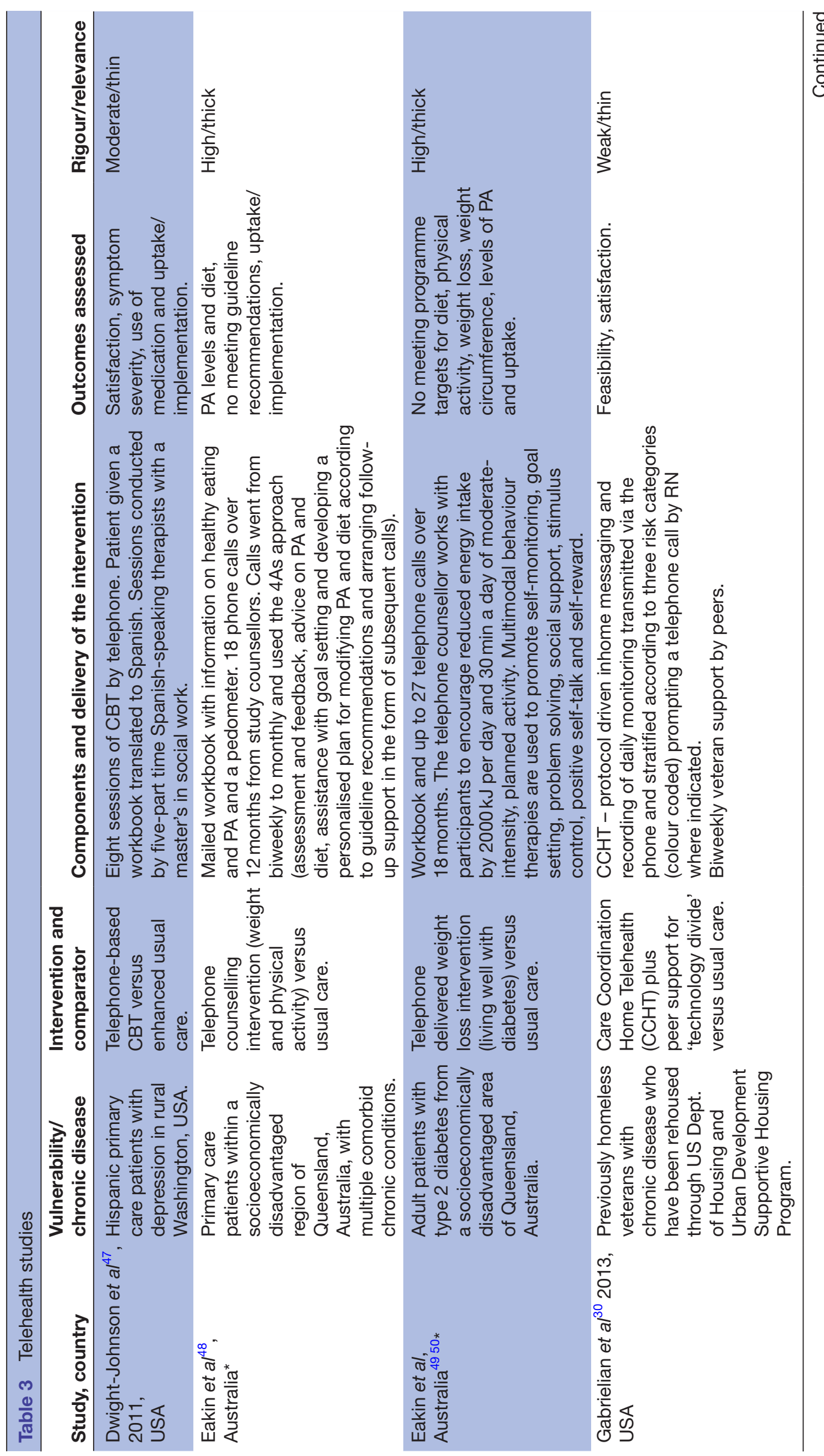




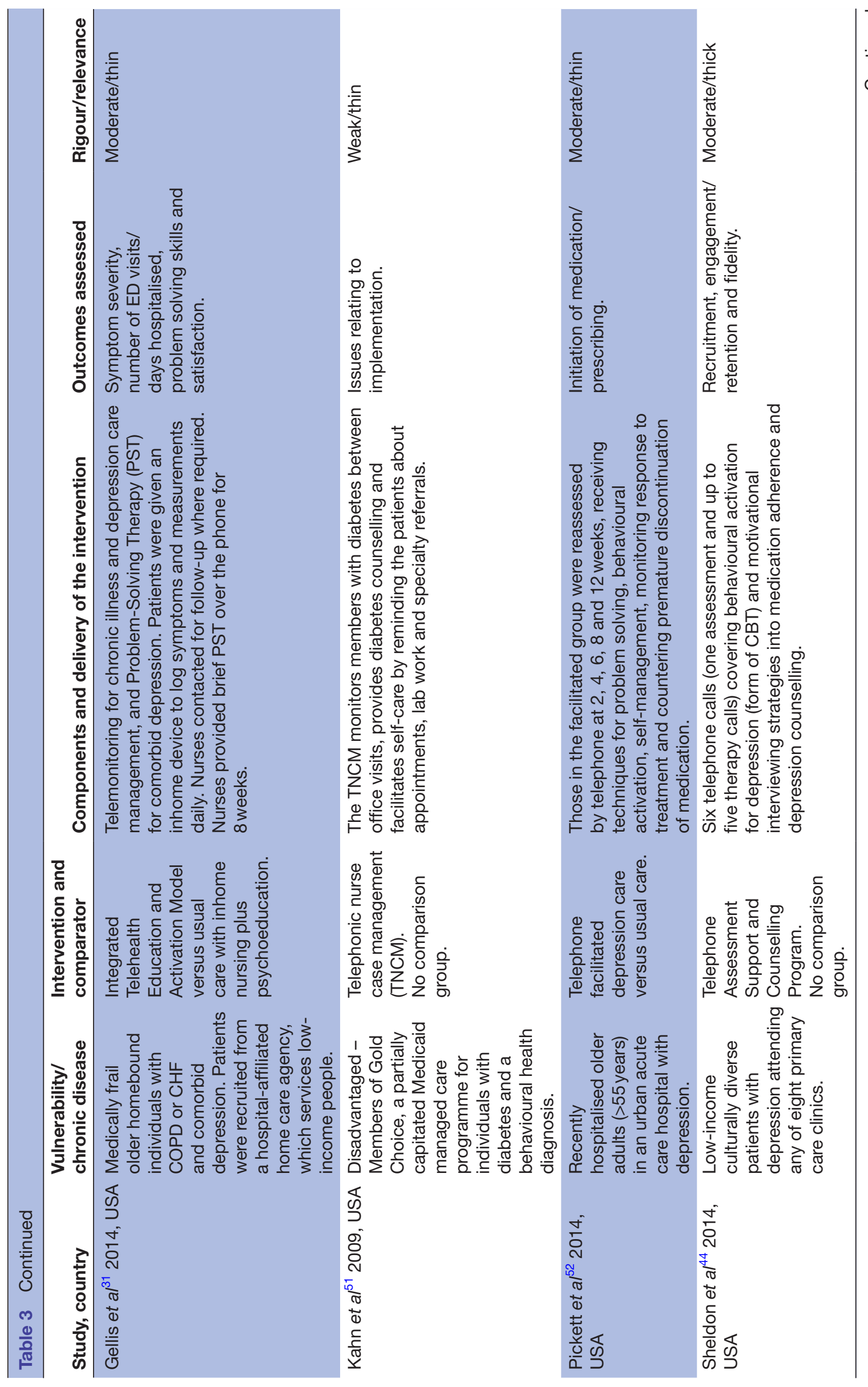



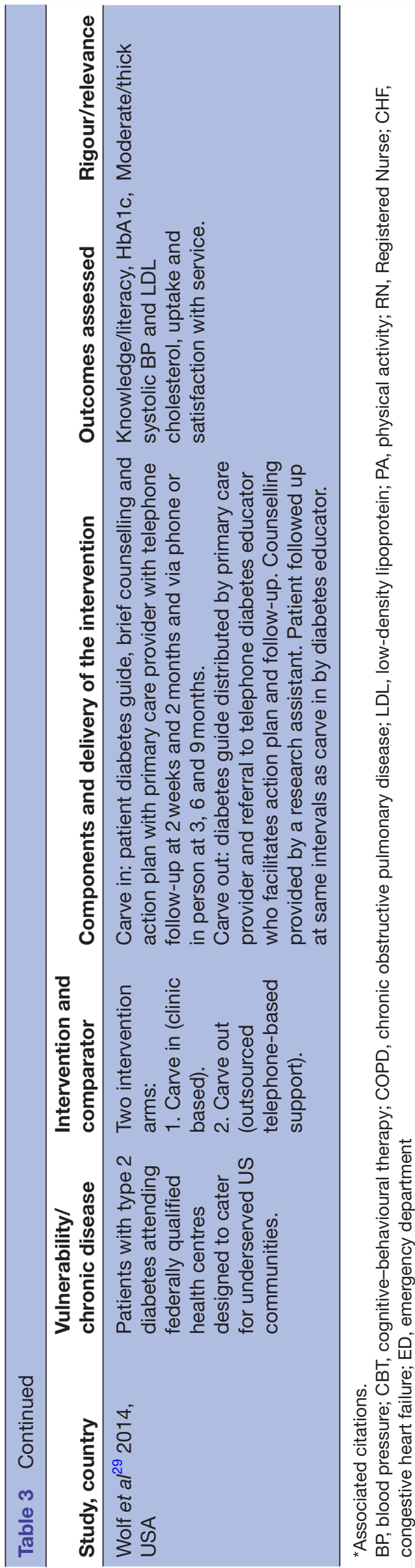

within the interventions targeted cognitive behavioural pursuits, reframing and increasing positive experiences and pleasurable activities.

\section{Contextual factors identified}

There was extensive contextual heterogeneity among the interventions (table 8). Patients were enrolled from a range of primary care settings (general practice, community health, supported veteran programmes, outpatient programmes, community home care and US federally funded health centres/Medicaid). The interventions were overwhelmingly home based and some unsupervised. Interventions targeted populations with a range of chronic conditions and vulnerabilities (older age $>55$ years, low socioeconomic status, difficulties with accommodation (previously homeless persons in supported accommodation, and rural communities with a mixture of lower socioeconomic and underserved populations). Studies largely were artificial environments where intervention providers were put in place specifically for the period of the research. In some studies, it was not possible to know the degree to which routine clinical/service staff were incorporated into the delivery of the intervention. Some services 'tagged' interventions onto existing service structure, and in many cases extra services and staff were temporarily employed to conduct interventions. Only one study ${ }^{32}$ had a system of 'organisational readiness' where significant time had been spent developing a mental health service that could provide depression treatment to patients.

Interactions involved a range of primary care providers (nurses, counsellors, diabetes educators, pharmacists and lay/peer workers). Although providers were predominantly nurses operating in a variety of roles, there was no evidence that this was associated with a different outcome to that of other providers. Surprisingly, general practitioners (GPs) (or their equivalents) did not deliver any of the interventions so no conclusions could be drawn about their role in delivering or negotiating these interventions with patients. Interventions were additional to the care of the GP or compared with the usual care provided by the GP. In some cases, enhanced usual care was used and in others the GP was peripheral to the main intervention activity in that they prescribed medications or reviewed guidelines with the patient or participated in dialogue with the intervention staff over management.

Nine studies were subcategorised as providing a purely telehealth intervention, seven combined eHealth elements with telehealth, one was a mix of mHealth and eHealth and one was predominantly mHealth (tables 4-7). All but one study provided a telephone-based service. Interventions were all multicomponent and designed to address one or more health disparity for underserved populations. In addition to telephone or video support, interventions provided a varied range of additional components including but not limited to: in home devices with prompts (6 studies), self-management education (15 studies), brief counselling (7 studies), ancillary patient devices (eg, pedometers, BP cuffs and blood glucose monitors) (6 studies), paper or 


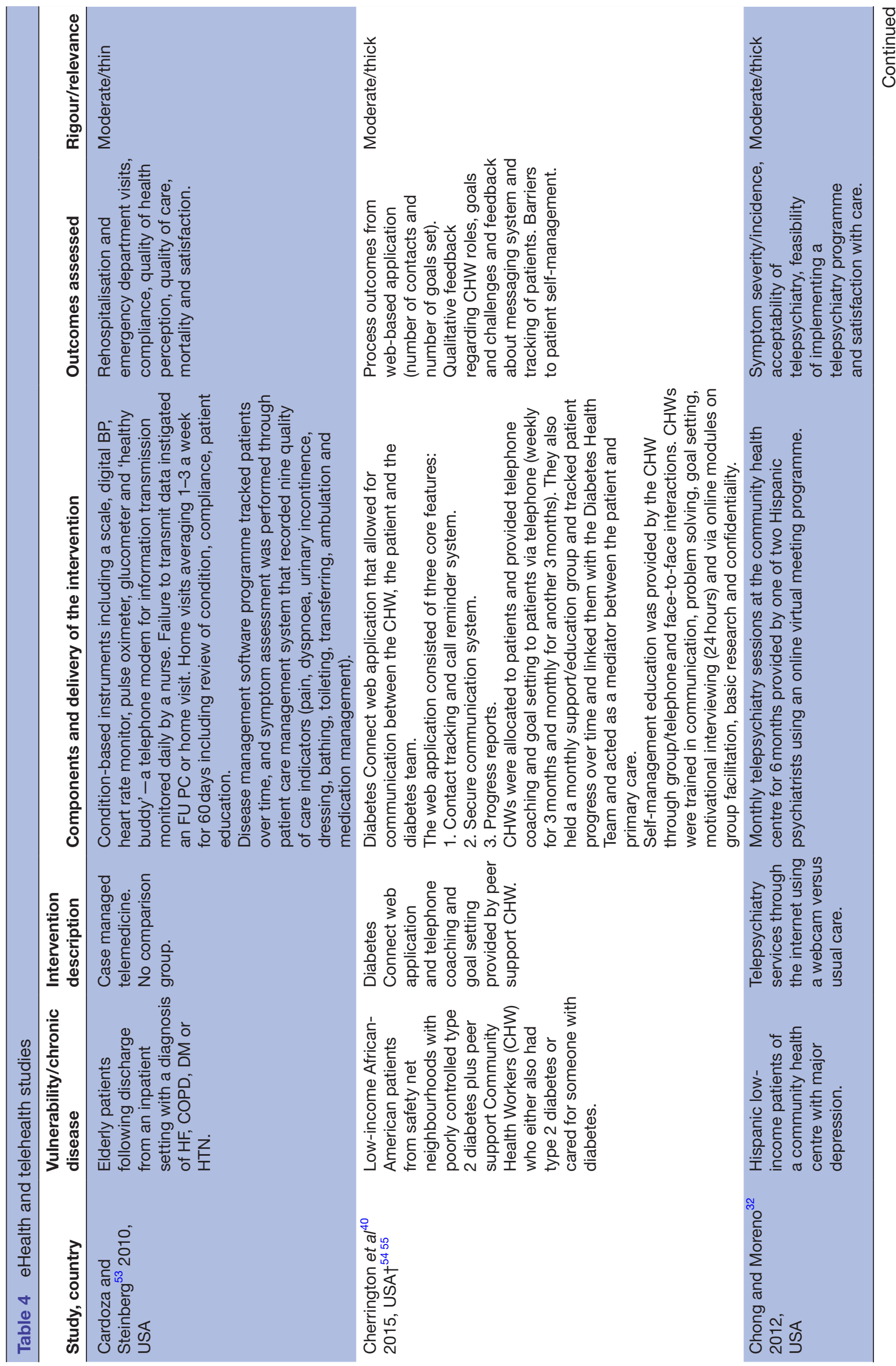




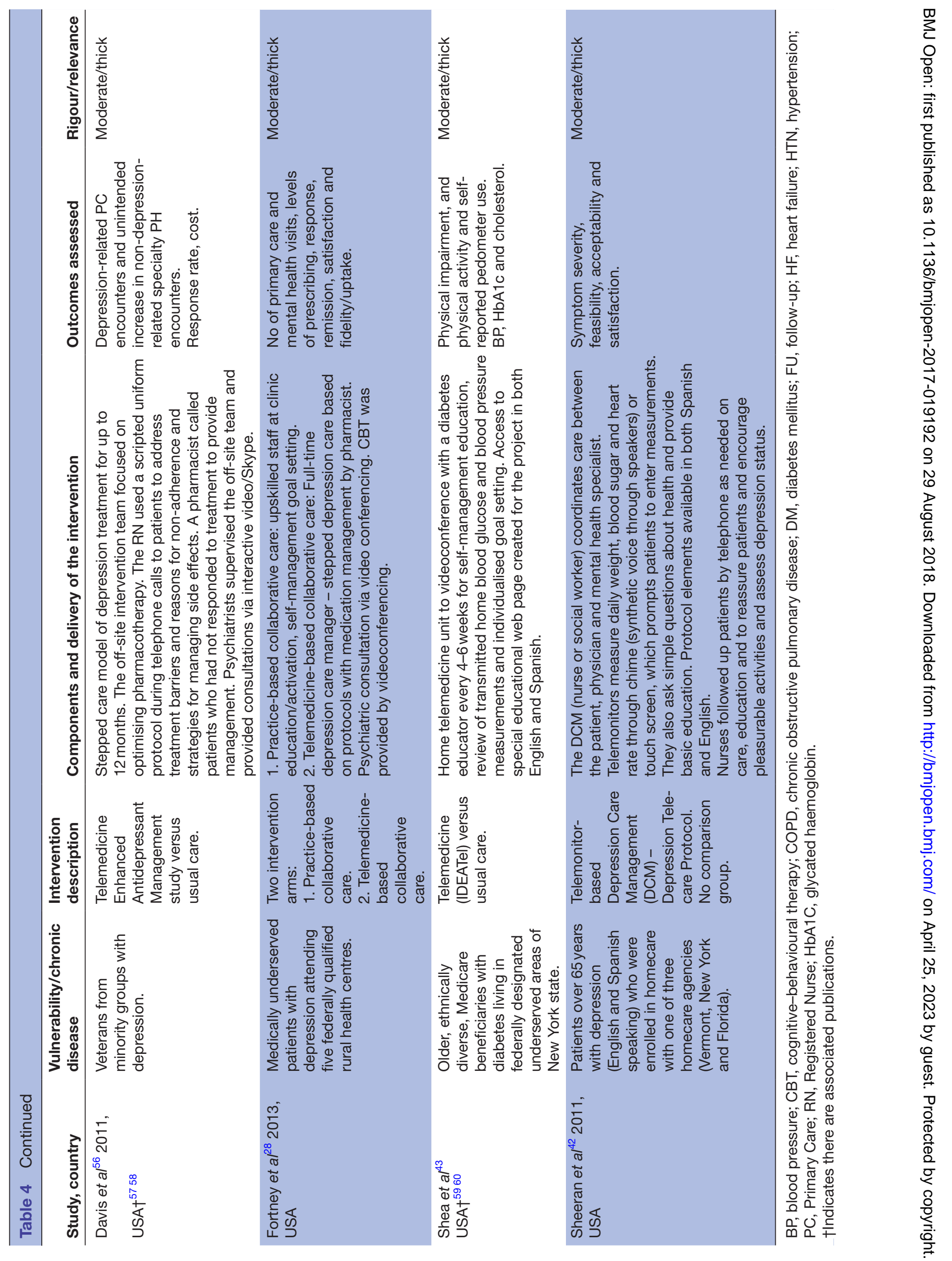


Table 5 mHealth studies

\begin{tabular}{|c|c|c|c|c|c|}
\hline Study, country & $\begin{array}{l}\text { Vulnerability/ } \\
\text { chronic disease }\end{array}$ & $\begin{array}{l}\text { Intervention } \\
\text { description }\end{array}$ & $\begin{array}{l}\text { Components and delivery of the } \\
\text { intervention }\end{array}$ & $\begin{array}{l}\text { Outcomes } \\
\text { assessed }\end{array}$ & $\begin{array}{l}\text { Rigour/ } \\
\text { relevance }\end{array}$ \\
\hline $\begin{array}{l}\text { Wayne, } 2015,{ }^{41} \\
\text { Canada }^{61}\end{array}$ & $\begin{array}{l}\text { Low SES } \\
\text { community } \\
\text { (multiracial) with } \\
\text { type } 2 \text { diabetes. }\end{array}$ & $\begin{array}{l}\text { Cloud-based } \\
\text { platform for } \\
\text { mobile phone/ } \\
\text { software- } \\
\text { based health } \\
\text { management } \\
\text { plus } \\
\text { smartphone- } \\
\text { based health } \\
\text { coaching } \\
\text { technology. }\end{array}$ & $\begin{array}{l}\text { Participants received a Samsung } \\
\text { Galaxy Ace II mobile phone } \\
\text { running on Google Android lce } \\
\text { Cream Sandwich (Android 4.0.2) } \\
\text { with a data-only carrier plan. } \\
\text { Patients received a user account } \\
\text { with the Connected Wellness } \\
\text { Platform (CWP) provided by } \\
\text { NexJ Systems, which supported } \\
\text { participants in health-related goal } \\
\text { setting and progress monitoring. } \\
\text { This allowed individual tracking } \\
\text { of key metrics, (blood glucose } \\
\text { levels, exercise frequency/ } \\
\text { duration/intensity, food intake } \\
\text { (via photo journaling) and mood). } \\
\text { HC primarily focused on planning } \\
\text { to reach health targets, exercise } \\
\text { (frequency, duration and intensity) } \\
\text { and modifying diet to to reduce } \\
\text { carbohydrate intake. } \\
\text { Communication with the HC } 24 / 7 \\
\text { via secure messaging, scheduled } \\
\text { phone contact, and/or during } \\
\text { inperson meetings. Health data } \\
\text { from the CWP were immediately } \\
\text { visible to HCs through a secure, } \\
\text { web-accessible portal. } \\
\text { Participant data and software- } \\
\text { enabled communication required } \\
\text { two-way certificate-based } \\
\text { authentication and passwords } \\
\text { that were stored in encrypted } \\
\text { bolumns. Based on patient's } \\
\text { after exercise sessions. } \\
\text { goals, HCs used the } 24 \text { hours/day } \\
\text { logging function to guide healthy } \\
\text { lifestyle choices, while providing } \\
\text { support when clients diverged } \\
\text { from intended health goals and } \\
\text { routines. }\end{array}$ & $\begin{array}{l}\text { HbA1c levels, } \\
\text { weight, } \\
\text { BMI, waist } \\
\text { circumference, } \\
\text { psychometric } \\
\text { assessment } \\
\text { (satisfaction, } \\
\text { QoL and } \\
\text { mood). }\end{array}$ & High/thick \\
\hline
\end{tabular}

BMI, body mass index; QoL, quality of life; SES, socioeconomic status; HF, heart failure, HbA1c, glycated haemoglobin.

electronic patient information resources (9 studies), medication management (7 studies), stepped care (2 studies) and bilingual providers (4 studies).

\section{Mechanisms}

Within realist synthesis, a mechanism is a response that is triggered by changes in context. ${ }^{13}$ Given the contextual heterogeneity, it was not possible to clearly identify these reactions.

The level of an individual's 'motivation' or 'activation' was one possible mechanism prompting patients to respond either positively or negatively to the situations in which the intervention was employed. ${ }^{35}{ }^{44}$ Feelings of 'being supported', 324044 having 'a sense of purpose', 44 experiencing 'a sense of achievement ${ }^{44}$ and the sharing of experiences ${ }^{33}$ are interwoven reactions that may serve to motivate people. It was difficult to know how the level of rapport/interaction between patient and provider contributed in these instances, although it was highlighted as an important contributor in some studies 2834244 and is a well-recognised enabling factor in self-efficacy and self-management programmes generally.

One study suggested that patients with limited motivation should be excluded from these types of 


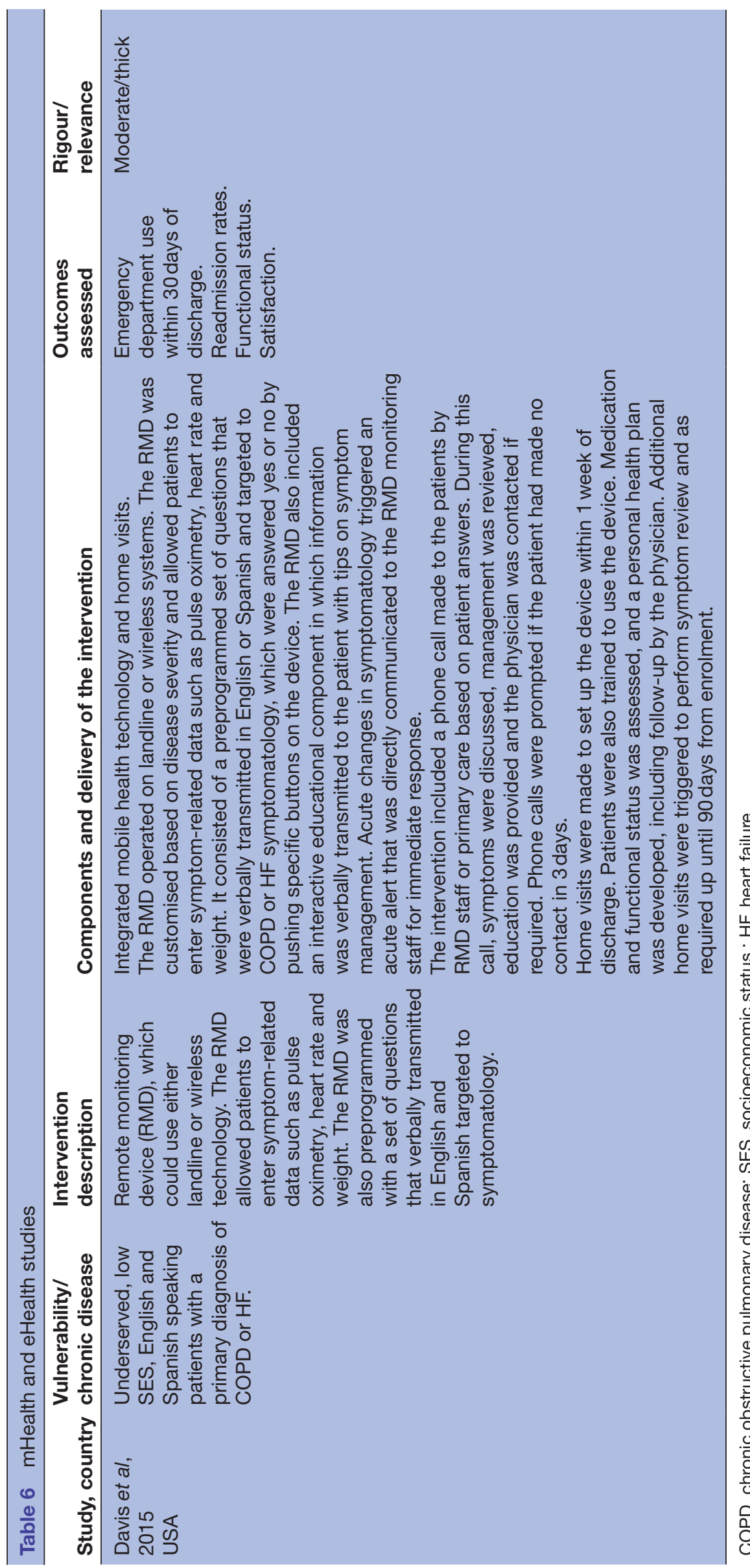




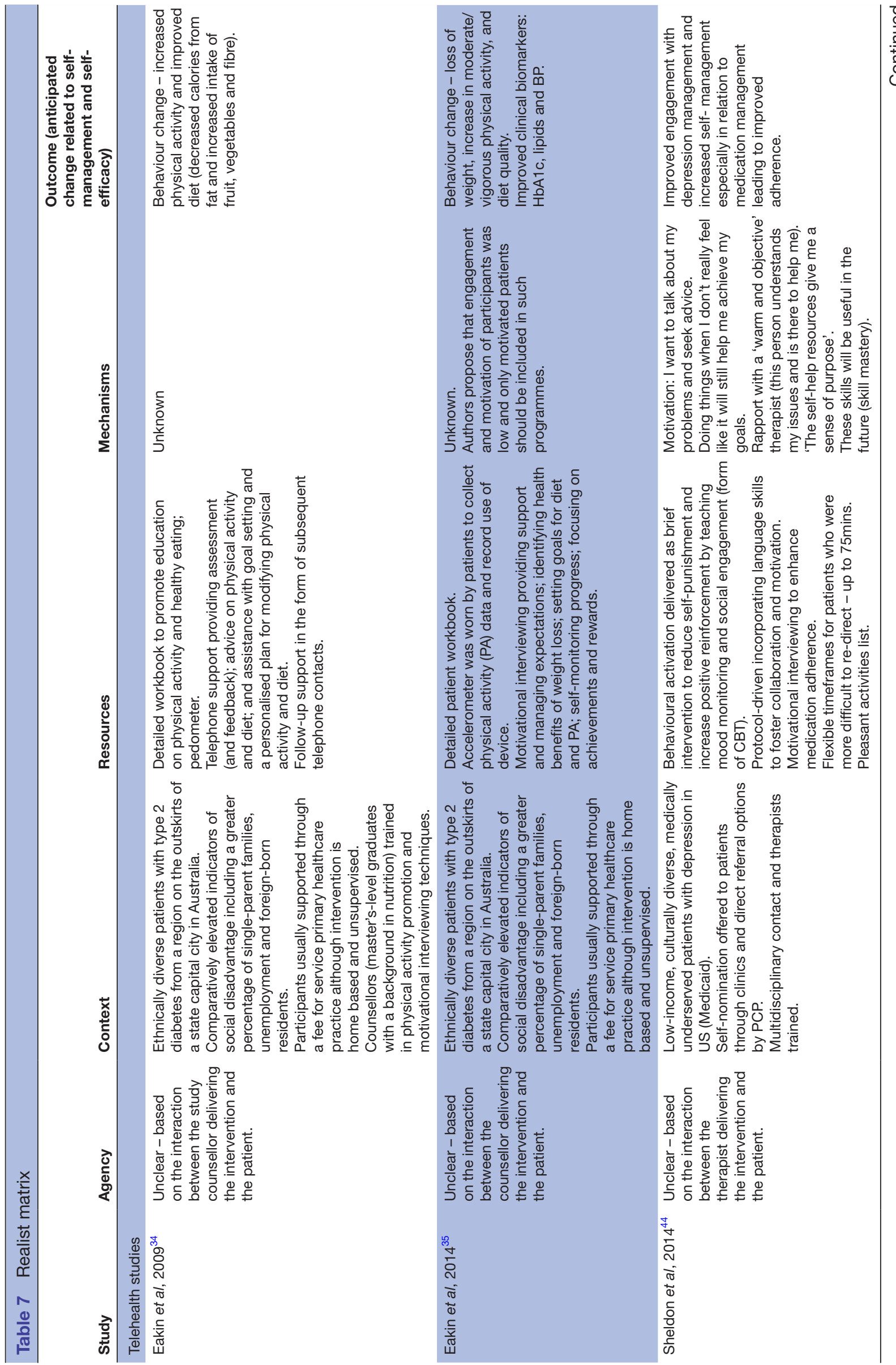




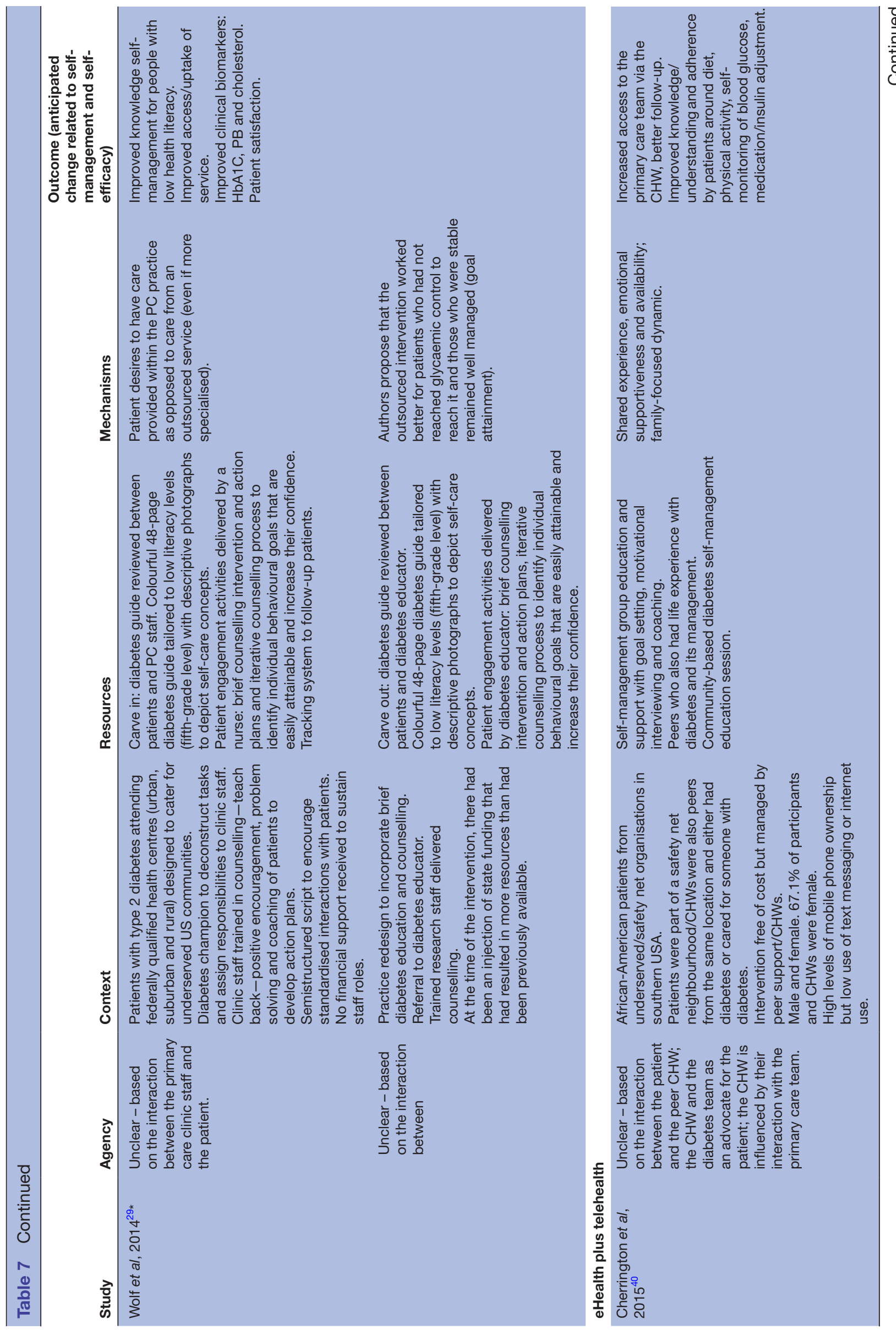




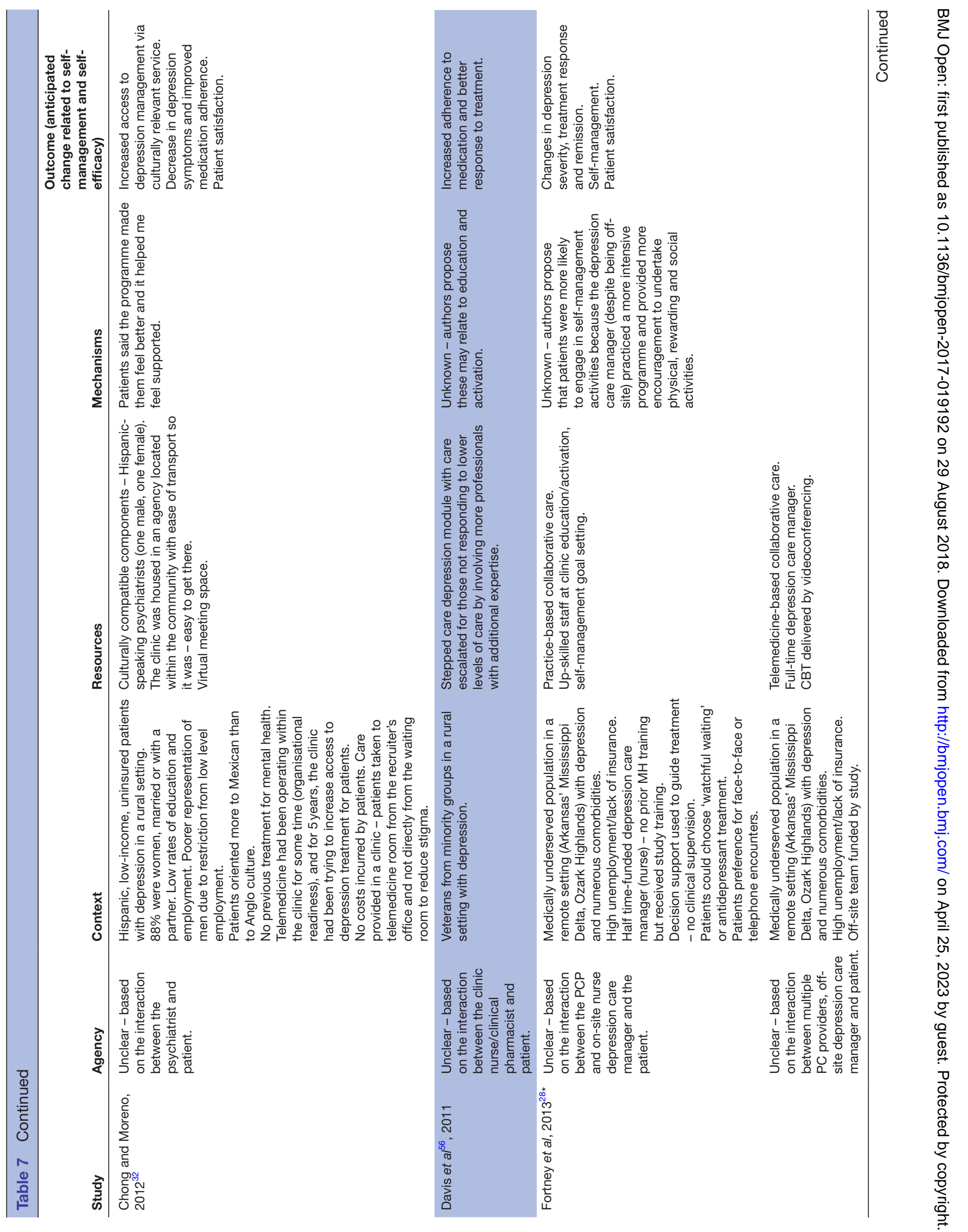




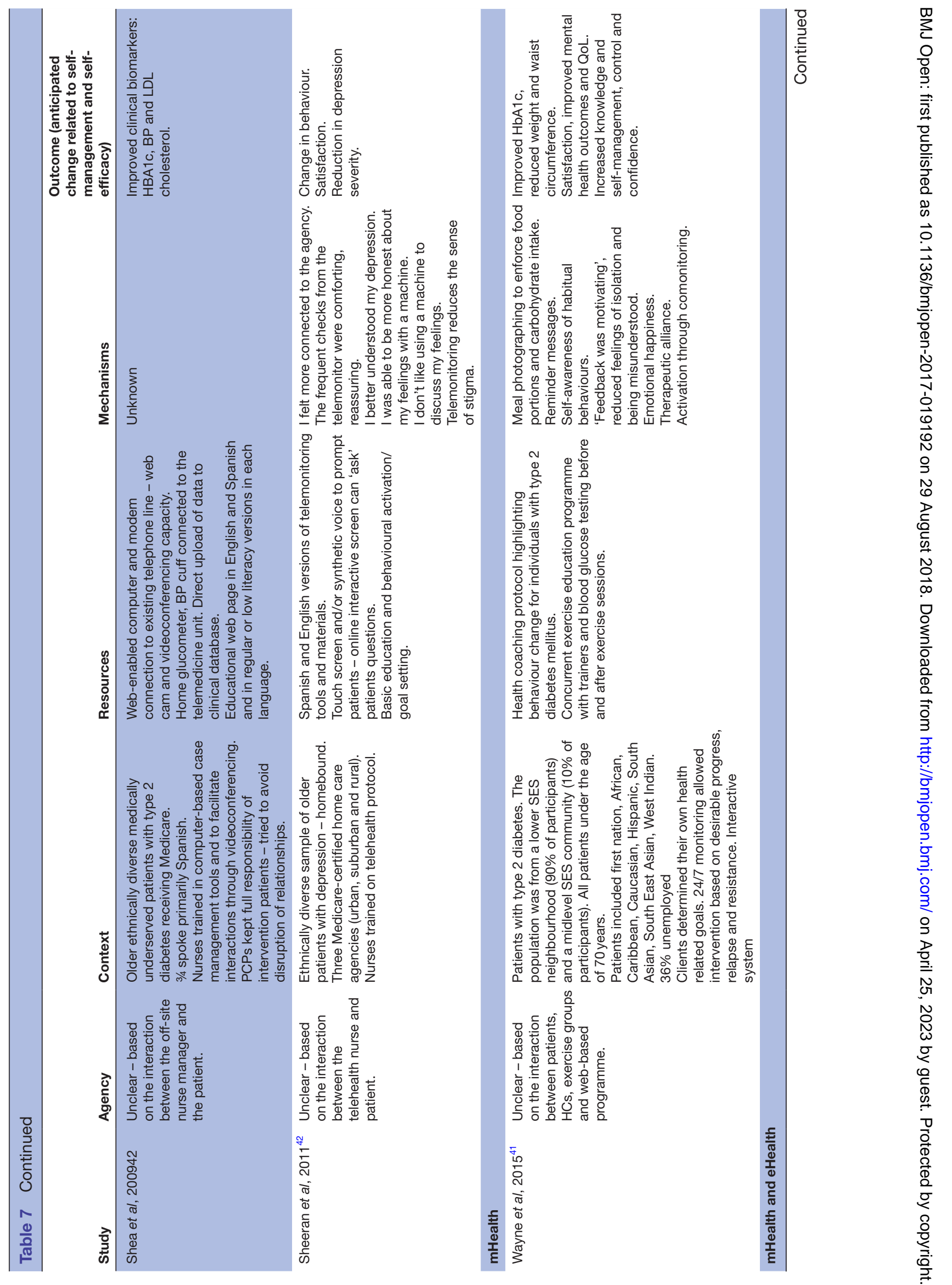


interventions, ${ }^{35}$ instead of providing efforts to 'kick start' motivation. Intuitively being motivated to seek assistance is a major driver in this process, but it is also a complex reaction in this type of population. Low levels of health literacy can affect the degree to which a person is motivated to act and equally low motivation can be construed as low health literacy. Only one study measured and/or categorised participants by their health literacy level. ${ }^{29}$ It is therefore not possible to comment how the levels of health literacy (or eHealth literacy) influenced participant response.

\section{Other contributing factors}

Despite a strong underlying certitude around the value of the interventions to produce improvements in patient self-efficacy and self-management, we identified from the studies a tendency for the intervention provider to be the dominant player within the interaction, and the patient a more passive participant.

Studies reported several barriers to the use and uptake of tools by patients. These included a general unease or mistrust with the use of technology ${ }^{42} 43$ and a preference for face-to-face contact on the part of patients ${ }^{32}$ and pressures of added workloads, ${ }^{44}$ reduced time and inadequate skills on the part of clinicians to take on additional roles. ${ }^{34}$ We found less age-related barriers in this review with elderly populations equally satisfied if interventions were well designed, user friendly and supported. We anticipated that the most significant enabling factor would be patient training. However, overall, we found the information relating to patient education and training to be sparse.

\section{DISCUSSION}

We identified 18 studies testing a variety of electronic, mobile and eHealth interventions with vulnerable populations. The included studies provided limited insight into the relationships between context, mechanisms and self-management outcomes related to these interventions. We identified a wide range of contextual factors and variation in the outcomes reported. Predominantly, the interventions sought to persuade patients into believing they could self-manage their conditions by encouraging goal setting, providing rewards for achievement, enhancing the patient's responsibility for symptom monitoring and providing education and additional support. Within this review, patients were viewed by providers as relatively passive, and the level of patient response directly aligned to their intrinsic level of motivation. Health literacy, which can often be confounded with motivation, was only measured in one study, and eHealth literacy was not assessed.

The provision of these tools to patients with chronic disease assumes that they directly impact on a patient's level of health literacy and subsequently their capacity to selfmanage their health conditions. The studies in this review however reported poorly on self-management and literacy outcomes, and we therefore do not know if the intensive 
Table 8 Characteristics of included studies

\begin{tabular}{|c|c|c|c|}
\hline Study characteristic & Number & Study characteristic & Number \\
\hline Design & & Setting & \\
\hline $\mathrm{RCT}$ & 9 & General practice & 6 \\
\hline Quality improvement & 1 & Supported veteran programme & 1 \\
\hline Observational & 2 & Outpatient programme & 1 \\
\hline Qualitative & 1 & Federally funded health centres/Medicaid & 2 \\
\hline Cohort & 2 & & \\
\hline Intervention & & Geographical area & \\
\hline Telehealth & 9 & USA & 15 \\
\hline eHealth and telehealth & 7 & Australia & 2 \\
\hline Chronic condition & & Vulnerability & \\
\hline Depression & 7 & Older age (>55 years) & 3 \\
\hline Diabetes & 6 & Low SES & 12 \\
\hline \multirow[t]{2}{*}{ Multimorbidity } & 5 & Homeless/supported accommodation & 1 \\
\hline & & Rural/low SES/underserved communities & 2 \\
\hline
\end{tabular}

RCT, randomised controlled trial; SES, socioeconomic status.

educational or behavioural activation components of the interventions identified were ultimately effective. Using tools to assess baseline health literacy and eHealth literacy levels may therefore be beneficial particularly if the intervention is tailored to individual needs and abilities. It would be highly valuable if future research could unpack this further since the mechanisms around this were largely unclear from this review, and the inter-relationship between these factors is highly complex. This is particularly true for those patients with competing physical and/or psychological morbidities.

These findings have implications for future implementation. Some studies have reported variable uptake and poor maintenance, leading some to suggest that these interventions be only offered to those with high levels of intrinsic motivation. ${ }^{35}$ An alternative would be to concentrate efforts on identifyingthe specific needs of vulnerable groups, and highly tailoring interventions to these needs to be more effective. This would seem to be indicated since we found reasonable levels of satisfaction and acceptance when patients perceived the intervention to be relevant to their needs, and adequately supported. We found no evidence of negative patient consequences from any of the interventions. Acceptance of health technology may also be related to a participants' understanding of their condition and their overall interest in their own health or health literacy. There was also some evidence to suggest that the level of acceptance was not consistent for all participants who fall into the 'vulnerable' category. It is possible that this relates to the many and varied contextual factors providing influence at a given time, such as competing health, social and cultural issues, although this could not be elaborated from this review.

Although these tools have been widely studied in the general population, we generally found a lack of studies involving vulnerable participants, particularly in groups speaking English as a second language. Most studies were conducted in the USA where social disadvantage was the major focus.

The strength of this review is a comprehensive search, the use of systematic processes to identify both quantitative and qualitative data and the use of Rameses publication standards as a basis for our reporting. ${ }^{19}$ We also incorporated a realist matrix and mapped our results according to self-efficacy theory to both determine and understand the mechanisms by which eHealth and telehealth influences self-efficacy and self-management for vulnerable patients with chronic disease. This withstanding, we found the realist component of this review challenging. The major drawback for this approach in our experience was the limited descriptions of context and mechanisms provided generally within published studies. The limited quantity of usable data inhibited our ability to effectively identify why these types of interventions worked (or did not work) differently across the varying primary healthcare contexts. Others have commented that the iterative and flexible methods required for realist reviews are at odds with the inflexible, structured processes inherent when conducting systematic reviews generally. ${ }^{13}$ Berg and Nanavati ${ }^{45}$ in a review of published realist reviews found that limitations frequently cited include the scarcity of detail around the mechanisms by which an intervention was expected to work and the 
diversity of contexts within studies that hamper generalisability. Developing the necessary skill set within the team, and sourcing appropriate guidance to perform a realist synthesis were also challenging. We chose to use a realist matrix and narrative summary because it provided a more structured process that we could follow. Others have also highlighted difficulties with incorporating realist methods, arguing that few studies incorporate it successfully while maintaining transparent and systematic methods because 'best practice' is under developed ${ }^{46}$ and there is currently little uniformity in practice. ${ }^{45}$

\section{CONCLUSIONS}

Although electronic, mobile and telehealth interventions have been widely assessed in several disease-specific groups covering the general population, specific research with vulnerable groups is much less comprehensive. Within the studies, the level of reported success was variable, but the reasons for this variation were not clear. Apart from intrinsic motivation, health literacy may be a factor influencing the reaction of vulnerable groups to technology. Symptom monitoring and management, goal setting, behavioural activation and motivational counselling were able to be successfully delivered by telephone or other modalities, but efforts to engage patients by healthcare providers were lower than expected.

Social persuasion and goal setting were the dominant components by which studies sought to achieve better self-management. Other theoretical aspects that underpin self-efficacy such as vicarious learning and interaction with similar people were less used but may warrant further research.

We would also encourage in future research some assessment of both health and eHealth literacy if including vulnerable populations, and further work to differentiate specific requirements for these groups that might differ to the general population when implementing health technologies.

Acknowledgements This review was conducted as part of the Innovative Models Promoting Access-to-Care Transformation (IMPACT) programme. The IMPACT investigators are: Prof Grant Russell, MonashUniversity and Southern Academic Primary Care Research Unit, Australia; A/Prof Jeannie Haggerty, McGillUniversity and St Mary's Research Centre, Canada; A/Prof Simone Dahrouge, Bruyère Research Institute and the University ofOttawa, Canada; Prof Mark Harris, Centre forPrimary Health Care and Equity, University of New South Wales, Australia; Dr Jean-Frederic Levesque, Bureau of Health Information and theUniversity of New South Wales, Australia; A/Prof Virginia Lewis, AustralianInstitute for Primary Care and Ageing, La Trobe University, Melbourne,Australia; A/Prof Catherine Scott, PolicyWisefor Children and Families and the University of Calgary, Canada; Professor Nigel Stocks, the Universityof Adelaide, Australia. We also acknowledge the commitment provided by theresearch teams and primary care communities from IMPACT sites in both Australiaand Canada. We would also like to thank Nila Sharma forassisting with the update of the search and retrieval of studies.

Collaborators The IMPACT Study Group: Professor Grant Russell; A/Professor Jeannie Haggerty; Dr Jean-Fred Levesque; Professor Mark Harris; A/Professor Simone Dahrouge; A/Professor Virginia Lewis; A/Professor Cathie Scott; and Professor Nigel Stocks.

Contributors SP contributed to the project methodology and design of the review, coordinated the review, designed and conducted the search, adjudicated and appraised studies, extracted and analysed data and drafted the manuscript. AP coordinated the deliberate forums and question development, designed and conducted the search, adjudicated and appraised studies, extracted and analysed data and reviewed the manuscript. LT and HS contributed to the search and the design of the analysis, extracted and analysed data and reviewed the draft manuscript. DM contributed to the question development through the LIP and reviewed the manuscript. MH contributed to the design of the IMPACT program of work, analysed and interpreted data and reviewed the manuscript. All authors have signed off on the final content of this manuscript.

Funding IMPACT is jointly funded by the Canadian Institutes of Health Research (TTF-130729) Signature Initiative in Community-Based Primary Health Care, the Fonds de recherche du Québec - Santé, and the Australian Primary Health Care Research Institute (Centre of Research Excellence), which is supported by a grant from the Australian Government Department of Health, under the Primary Health Care Research, Evaluation and Development Strategy. The information and opinions contained in this paper do not necessarily reflect the views or policy of these funding agencies. The authors have not declared a specific grant for this research from any funding agency in the public, commercial or not-for-profit sectors.

Competing interests None declared.

Patient consent Not required.

Provenance and peer review Not commissioned; externally peer reviewed.

Data sharing statement № additional data are available. Data extracted from included studies relevant to the discussion in this manuscript have been provided in tables 4-7.

Open access This is an open access article distributed in accordance with the Creative Commons Attribution Non Commercial (CC BY-NC 4.0) license, which permits others to distribute, remix, adapt, build upon this work non-commercially, and license their derivative works on different terms, provided the original work is properly cited and the use is non-commercial. See: http://creativecommons.org/ licenses/by-nc/4.0/

(c) Article author(s) (or their employer(s) unless otherwise stated in the text of the article) 2018. All rights reserved. No commercial use is permitted unless otherwise expressly granted.

\section{REFERENCES}

1. Gee PM, Greenwood DA, Paterniti DA, et al. The eHealth enhanced chronic care model: a theory derivation approach. J Med Internet Res 2015;17:e86.

2. Voncken-Brewster $\mathrm{V}$, Tange $\mathrm{H}$, Moser $\mathrm{A}$, et al. vdW: integrating a tailored e-health self-management application for chronic obstructive pulmonary disease patients into primary care: a pilot study. BMC Family Practice 2014:415.

3. Gomez Quiñonez S, Walthouwer MJ, Schulz DN, et al. mHealth or ehealth? Efficacy, use, and appreciation of a web-based computertailored physical activity intervention for dutch adults: a randomized controlled trial. J Med Internet Res 2016;18:e278.

4. Georgeff M. Digital technologies and chronic disease management. Aust Fam Physician 2014;43:842-6.

5. Royal australian college of general practitioners (RACGP). The racgp curriculum for australian general practice 2011. Melbourne: RACGP, 2011.

6. Mackert M, Champlin SE, Holton A, et al. eHealth and health literacy: a research methodology review. Journal of Computer-Mediated Communication 2014;19:516-28.

7. Kim H, Xie B. Health literacy in the eHealth era: a systematic review of the literature. Patient Educ Couns 2017;100:1073-82.

8. Ciere Y, Cartwright M, Newman SP. A systematic review of the mediating role of knowledge, self-efficacy and self-care behaviour in telehealth patients with heart failure. $J$ Telemed Telecare 2012;18:384-91.

9. Adams K, Corrigan JM. Priority areas for national action: transforming health care quality. Washington (DC): National Academies Press (US): Institute of Medicine (US) Committee on Identifying Priority Areas for Quality Improvement, 2003.

10. Rollnick S, Miller WR, Butler CC. Motivational interviewing in health care: helping patients change behavior. New York: The Guilford Press, 2008.

11. Bartlett M, Basten R, McKinley RK. Green shoots of recovery: a realist evaluation of a team to support change in general practice. BMJ Open 2017;7:e014165. 
12. Pawson R, Greenhalgh T, Harvey G, et al. Realist review-a new method of systematic review designed for complex policy interventions. J Health Serv Res Policy 2005;10(Suppl 1):21-34

13. Saul JE, Willis CD, Bitz J, et al. A time-responsive tool for informing policy making: rapid realist review. Implement Sci 2013;8:103.

14. National Public Health Partnership. Prevention chronic disease: a strategic framework background paper. 2001.

15. World Health Organization. Glossary of globalization trade and health terms. http://www.who.int/trade/glossary/en/.

16. Australian Government Department of Health. Telehealth. http:// health.gov.au/internet/main/publishing.nsf/Content/e-healthtelehealth.

17. Centre for Reviews and Dissemination. Systematic reviews. CRD's guidance for undertaking reviews in health care. York, UK: CRD, University of York, 2009.

18. Rycroft-Malone J, McCormack B, Hutchinson AM, et al. Realist synthesis: illustrating the method for implementation research. Implement Sci 2012;7:1-22.

19. Wong G, Greenhalgh T, Westhorp G, et al. RAMESES publication standards: realist syntheses. BMC Medicine 2013;11:1-14.

20. Moher D, Liberati A, Tetzlaff J, et al. Preferred reporting items for systematic reviews and meta-analyses: the PRISMA statement. PLoS Med 2009;6:e1000097.

21. Glasgow RE, McKay HG, Piette JD, et al. The RE-AIM framework for evaluating interventions: what can it tell us about approaches to chronic illness management? Patient Educ Couns 2001;44:119-27.

22. Hoffmann TC, Glasziou PP, Boutron I, et al. Better reporting of interventions: template for intervention description and replication (TIDieR) checklist and guide. BMJ 2014;348:g1687.

23. O'Neill J, Tabish $\mathrm{H}$, Welch $\mathrm{V}$, et al. Applying an equity lens to interventions: using PROGRESS ensures consideration of socially stratifying factors to illuminate inequities in health. $J$ Clin Epidemiol 2014;67:56-64.

24. Kastner M, Estey E, Perrier L, et al. Understanding the relationship between the perceived characteristics of clinical practice guidelines and their uptake: protocol for a realist review. Implement Sci 2011;6:1-9.

25. O'Campo P, Kirst M, Tsamis C, et al. Implementing successful intimate partner violence screening programs in health care settings: evidence generated from a realist-informed systematic review. Soc Sci Med 2011;72:855-66.

26. Pawson R, Greenhalgh T, Harvey G, et al. Realist synthesis: an introduction. University of Manchester: ESRC Research Methods Programme Working Paper Series 2004, 2004.

27. Realist matrix. http://betterevaluation.org/evaluation-options/realist_ matrix

28. Fortney JC, Pyne JM, Mouden SB, et al. Practice-based versus telemedicine-based collaborative care for depression in rural federally qualified health centers: a pragmatic randomized comparative effectiveness trial. Am J Psychiatry 2013;170:414-25

29. Wolf MS, Seligman H, Davis TC, et al. Clinic-based versus outsourced implementation of a diabetes health literacy intervention. J Gen Intern Med 2014;29:59-67.

30. Gabrielian S, Yuan A, Andersen RM, et al. Chronic disease management for recently homeless veterans: a clinical practice improvement program to apply home telehealth technology to a vulnerable population. Med Care 2013;51(3 Suppl 1):S44-51.

31. Gellis ZD, Kenaley BL, Ten Have T. Integrated telehealth care for chronic illness and depression in geriatric home care patients: the Integrated Telehealth Education and Activation of Mood (I-TEAM) study. J Am Geriatr Soc 2014;62:889-95.

32. Chong J, Moreno F. Feasibility and acceptability of clinic-based telepsychiatry for low-income Hispanic primary care patients. Telemed J E Health 2012;18:297-304.

33. Davis C, Bender M, Smith T, et al. Feasibility and acute care utilization outcomes of a post-acute transitional telemonitoring program for underserved chronic disease patients. Telemed J E Health 2015;21:705-13.

34. Eakin E, Reeves M, Lawler S, et al. Telephone counseling for physical activity and diet in primary care patients. Am J Prev Med 2009;36:142-9.

35. Eakin EG, Winkler EA, Dunstan DW, et al. Living well with diabetes: 24-month outcomes from a randomized trial of telephone-delivered weight loss and physical activity intervention to improve glycemic control. Diabetes Care 2014;37:2177-85.

36. Bandura A. Self-efficacy: toward a unifying theory of behavioral change. Psychol Rev 1977;84:191-215.

37. Bandura A. Self-efficacy: the exercise of control. New York: W.H Freeman, 1997

38. Lorig KR, Holman H. Self-management education: history, definition, outcomes, and mechanisms. Ann Behav Med 2003;26:1-7.
39. Hoffman AJ. Enhancing self-efficacy for optimized patient outcomes through the theory of symptom self-management. Cancer Nurs 2013;36:E16-E26.

40. Cherrington AL, Agne AA, Lampkin Y, et al. Diabetes Connect: developing a mobile health intervention to link diabetes community health workers with primary care. J Ambul Care Manage 2015;38:333-45

41. Wayne N, Perez DF, Kaplan DM, et al. Health coaching reduces hba1c in type 2 diabetic patients from a lower-socioeconomic status community: a randomized controlled trial. J Med Internet Res 2015;17:e224.

42. Sheeran T, Rabinowitz T, Lotterman J, et al. Feasibility and impact of telemonitor-based depression care management for geriatric homecare patients. Telemed J E Health 2011;17:620-6.

43. Shea S, Weinstock RS, Teresi JA, et al. IDEATel Consortium. A randomized trial comparing telemedicine case management with usual care in older, ethnically diverse, medically underserved patients with diabetes mellitus: 5 year results of the IDEATel study. J Am Med Inform Assoc 2009;16:446-56.

44. Sheldon C, Waxmonsky JA, Meir R, et al. Telephone assessment, support, and counseling for depression in primary care medical clinics. Cogn Behav Pract 2014;21:282-95.

45. Berg R, Nanavati J. Realist review: current practice and future prospects. Journal of Research Practice 2016;12.

46. Walker D, Bergh G, Page E, et al. Adapting systematic reviews for social research in international development: a case study on child protection. Shaping Policy for Development 2013. The Overseas Development Institute (UKindependent think tank on international development and humanitarianissues).

47. Dwight-Johnson M, Aisenberg E, Golinelli D, et al. Telephone-based cognitive-behavioral therapy for Latino patients living in rural areas: a randomized pilot study. Psychiatr Serv 2011;62:936-42.

48. Eakin EG, Reeves MM, Lawler SP, et al. The logan healthy living program: a cluster randomized trial of a telephone-delivered physical activity and dietary behavior intervention for primary care patients with type 2 diabetes or hypertension from a socially disadvantaged community-rationale, design and recruitment. Contemp Clin Trials 2008;29:439-54

49. Eakin EG, Reeves MM, Winkler E, et al. Six-month outcomes from living well with diabetes: a randomized trial of a telephone-delivered weight loss and physical activity intervention to improve glycemic control. Ann Behav Med 2013;46:193-203.

50. Eakin EG, Reeves MM, Marshall AL, et al. Living well with diabetes: a randomized controlled trial of a telephone-delivered intervention for maintenance of weight loss, physical activity and glycaemic control in adults with type 2 diabetes. BMC Public Health 2010;10:452.

51. Kahn LS, Fox CH, Carrington J, et al. Telephonic nurse case management for patients with diabetes and mental illnesses: a qualitative perspective. Chronic IIIn 2009;5:257-67.

52. Pickett YR, Kennedy GJ, Freeman K, et al. The effect of telephonefacilitated depression care on older, medically ill patients. J Behav Health Serv Res 2014;41:90-6.

53. Cardozo L, Steinberg J. Telemedicine for recently discharged older patients. Telemed J E Health 2010;16:49-55.

54. Crabtree K, Sherrer N, Rushton T, et al. Diabetes connect: African American men's preferences for a community-based diabetes management program. Diabetes Educ 2015;41:118-44.

55. Richardson BS, Willig AL, Agne AA, et al. Diabetes connect: African American women's perceptions of the community health worker model for diabetes care. J Community Health 2015;40:905-11.

56. Davis TD, Deen T, Bryant-Bedell K, et al. Does minority racial-ethnic status moderate outcomes of collaborative care for depression? Psychiatr Serv 2011;62:1282-8.

57. Fortney JC, Maciejewski ML, Tripathi SP, et al. A budget impact analysis of telemedicine-based collaborative care for depression. Med Care 2011;49:872-80.

58. Pyne JM, Fortney JC, Tripathi SP, et al. Cost-effectiveness analysis of a rural telemedicine collaborative care intervention for depression. Arch Gen Psychiatry 2010;67:812-21.

59. Weinstock RS, Teresi JA, Goland R, et al. IDEATel Consortium. Glycemic control and health disparities in older ethnically diverse underserved adults with diabetes: five-year results from the Informatics for Diabetes Education and Telemedicine (IDEATel) study. Diabetes Care 2011;34:274-9.

60. Izquierdo RE, Wang D, Huang D, et al. Case Management with a Diabetes Team Using Home Telemedicine: Acceptance of Treatment Recommendations by Primary Care Providers in IDEATel. Telemed $J$ E Health 2015;21:980-6.

61. Pludwinski S, Ahmad F, Wayne N, et al. Participant experiences in a smartphone-based health coaching intervention for type 2 diabetes: A qualitative inquiry. J Telemed Telecare 2016;22:172-8. 